
Educational Development

\author{
Jennifer Ahern-Dodson and Monique Dufour
}

\begin{abstract}
In this article, we explore how supporting faculty writers can also help them to become more effective teachers of writing in their disciplines. Based on over 10 years of facilitating and studying faculty at our writing retreats, we demonstrate how faculty understanding and improving their own writing experiences can spark insight into their students as writers. Furthermore, we suggest that helping faculty make this "turn to teaching" exemplifies the potential for an integrative model of educational development, one that leverages connections across faculty roles and responsibilities.
\end{abstract}

Keywords: Faculty writers, writing retreats, writing in the disciplines, educational development, experiential learning.

Educational developers have increasingly addressed the needs of faculty as writers. After all, faculty writers, like students, need and deserve support in order to have meaningful, productive writing experiences (Belcher, 2009; Elbow \& Sorcinelli, 2006; Geller \& Eodice, 2013; Simmons \& Singh, 2019; Sorcinelli et al., 2011). Faculty writing initiatives are prevalent, diverse, and widespread and seem only to be gaining momentum. At many universities, institutional units such as centers for 
teaching and learning, writing programs, writing centers, and provosts' offices sponsor campus writing retreats and faculty writing groups. Geller and Eodice's edited collection Working with Faculty Writers (2013) documents the wide spectrum of activities proliferating at a range of institutions and for faculty in a range of career stages, disciplines, position types, and ranks.

Beyond university-based offerings, faculty can and do participate in external programs. Many independent consultants specialize in faculty writing support. Michelle Boyd's InkWell retreats and Kel Weinhold's Unstuck programs are popular and well regarded. The National Center for Faculty Development and Diversity (NCFDD) has over 200 institutional members, whose faculty can access many webinars, accountability software, and 14-day writing challenges; NCFDD tenure-track or tenured faculty can purchase participation in the 12-week Faculty Success Program.

Faculty can also fill their shelves with many useful books, such as How to Write A Lot, Write No Matter What, and Publish and Flourish (Gray, 2005; Jensen, 2017; Silva, 2007). In 1990, Robert Boice's Professors as Writers seemed like the lone book of its kind, and it later sat beside cherished copies of Anne Lamott's Bird by Bird and Natalie Goldberg's Writing Down the Bones. Currently, most major university presses publish how-to books for faculty writers, who are clearly buying them.

Research on these interventions has focused primarily on the extent to which they increase academic publication rates and satisfaction. For instance, in a review of 17 studies, McGrail et al. (2006) report that writing retreats, writing support groups, and writing coaches all increased faculty productivity. Studies of writing retreats in particular suggest retreats increase motivation to write (Moore, 2003), foster a sense of community (Geller \& Eodice, 2013), help faculty develop effective strategies, and enhance productivity (Murray \& Newton, 2009).

Since 2012, we have led an annual, multi-institutional, four-day scholarly writing retreat. We come to this work as experienced teachers 
and faculty developers. Ahern-Dodson has a PhD in writing studies with a faculty appointment in a writing program; leads a university-based faculty writing initiative; and has consulted extensively with faculty on assignment design, curriculum, and assessment. Dufour has interdisciplinary graduate training, including a $\mathrm{PhD}$ in science and technology studies; has worked as a faculty development consultant and writing across the curriculum administrator; and has a faculty appointment in history. Based at a program for faculty writers at an R1 university, our annual writing retreat enrolls participants across career stages, disciplines, and institution types. Their writing projects have included journal articles, book chapters, grant applications, tenure portfolios, plays, books, and conference presentations. They come from R1 private and public institutions, regional state institutions, four-year colleges, and historically black colleges and universities.

Before the retreat begins, we ask writers to tell us what project they plan to work on, their writing goals for the summer, and what they would like to change or improve about their writing experiences. We design the retreat to address the participants' expressed goals as well as to help them reflect on their current goals and practices and to experiment with new ones. Each day of the retreat includes independent writing time, group discussions, and writing workshops focused on advancing productivity as well as increasing satisfaction and a sense of empowerment with the writing process once the retreat is over. In other words, our retreats emphasize getting things done and feeling a sense of agency, community, and meaning in the process, now and in the future. Retreats always fill quickly, and many participants return year after year, bringing colleagues.

Since 2012, we have researched these retreats. (IRB approval for this research was obtained through Duke University Protocol 0492, Scholarly Writing Support Programs and D0782, Summer Writing Pilot.) Using pre- and post-program survey data to estimate impacts of the program on participants' writing dispositions and productivity, we learned from writers that the retreats have five key outcomes: (1) advanced their scholarly products; (2) increased their engagement 
with writing during and after the retreat; (3) lessons and practices learned at the retreat reinforced positive dispositions toward writing; (4) helped decrease writing challenges such as "writing block"; and (5) increased sense of belonging and identity as a faculty-scholar. These outcomes echo the research and literature on effective faculty writing retreats (Girardeau et al., 2014; Maheux-Pelletier et al., 2019; Moore et al., 2010).

In this article, we share an additional surprising and novel discovery that we made during these retreats: when we empower faculty as writers, we can also empower them as teachers of writing in their disciplines. When we help faculty to apply their insights about their writing to their teaching, we call this moment "the turn to teaching." Furthermore, we suggest that helping faculty make this connection exemplifies the potential for an integrative model of faculty development.

In How Writing Faculty Write, Tulley (2018) posed questions to drive next steps in the research and practice of supporting faculty as writers: "What do our writing practices mean for our teaching practices? ... How do our writing habits and feelings toward writing affect our professional practices and vice versa?" (p. 149). We see the turn to teaching as a way of opening spaces for faculty to ask these questions and make these connections between their own writing and their teaching and professional practices. The turn to teaching becomes possible when we help faculty to understand their own writing "habits and feelings." The turn to teaching arises out of their own authentic learning about writing.

Here we share a series of stories about faculty with whom we have worked over the years in our writing retreats, workshops, and consultations. In the first two sections, we explore how two faculty writers learned new, effective approaches to their work and how they applied that learning to their teaching. We have chosen to construct this article around narrative and case analysis because we want to show insightin-action as a process that happens within faculty in real time, which cannot be effectively described or analyzed for our purposes as a number or aggregate data. We then discuss some of the most common 
connections that we have helped faculty to make between teaching and writing. Finally, we explain how the turn to teaching exemplifies a promising integrative model of faculty development.

\section{Retreat Design}

Our retreats are designed to promote authentic learning about writing. The turn to teaching arises out of that authentic learning. The retreats have several key features to optimize both. Retreats take place over at least two days in a row and are scheduled when faculty can focus on their writing, such as during the summer or after the close of a semester. Retreat leaders are also teachers and writers. Throughout the retreat, the retreat leaders seek out opportunities to point out connections between participants' insights about writing and their teaching. We also offer optional in-retreat breakouts and post-retreat follow-up workshops that explore those connections. ${ }^{1}$

All our interactions with faculty writers are based on five foundational principles:

1. Faculty as autonomous knowers. Each participant has the autonomy to choose what they work on and how they use their time during the retreat. They arrive with knowledge, expertise, and wisdom about their disciplines, their intellectual work, and their professional and life contexts.

2. Supportive, honest, and accepting community. We promote a nonjudgmental, non-hierarchical, and non-competitive space. Everyone commits to an honest exploration of how writing happens-and doesn't happen. We do not focus on productivity but on progress, meaning, and satisfaction, which helps to tamp down performative

1. Post-retreat workshops have addressed pedagogical topics such as "Applying Retreat Insights to Your Teaching" and "Teaching with TIME in Mind." In May 2020, we held our first "alumni only" weeklong retreat, and during the upcoming academic year, we will offer advanced workshops for retreat alumni, thus creating a scaffolded curriculum that further supports our integrative, insight-driven approach. 
competitiveness around writing and publication. The retreats allow participants to show up authentically and be together in the common enterprise of making progress on their work.

3. Shared language. We establish concepts and phrases that writers can use to describe and analyze their own writing process. This shared language intervenes in common misconceptions about the writing process and gives writers new ways to interpret what's happening and to take positive action. Shared language also builds community, as it gives participants effective ways to communicate as writers.

4. Repertoire, not rules. There are many ways to write well. We help faculty to identify their current writing repertoire, to assess how and when their current strategies work, and to expand their range of choices in order to do the work they want to do under shifting conditions (Dufour \& Ahern-Dodson, 2017; Sword, 2017).

5. Reflective practice. We invite reflection so that faculty can constitute their own experiences as an object of analysis. In particular, we help them to see and analyze their dominant beliefs about what good writing is and how it happens. These dominant beliefs often drive their actions, shape their experiences, and determine their results. Throughout the retreats, following writing sessions or workshops, we pause to help people to reflect on the experience in ways that help them to understand themselves and to make more effective choices. They can try new ideas and techniques in a safe environment and explore the results in light of their own experience and progress toward their goals (Werder, 2013). ${ }^{2}$

The turn to teaching can be powerful, but there are important issues to keep in mind as we explore its potential. We offer four caveats:

1. We are not suggesting that programming for faculty writers should also always address teaching or, more broadly, that any programming

2. Jennifer Ahern-Dodson and Monique Dufour, "Faculty Development for Writers as Metacognitive Learning," article in progress. 
for one domain of faculty lives and work should be optimized by also addressing others. An integrative model relies less on combining disparate things than on providing spaces and tools for faculty to make authentic connections between their own lived experiences of writing and the lived experiences of their students as writers.

2. The turn to teaching relies on the facilitator to make judgments about how and when to help faculty to make connections through guided reflection. Like all learning that arises from reflection and insight, it is very hard to program in a standardized way. It doesn't happen at the same time for everyone, if at all. Sustained opportunities for facilitated support after the retreat ends also serve faculty well as they explore how to apply their insights to working with students.

3. It's optional. Faculty decide if they want to explore these connections. In programming about writing, faculty may need and want to focus exclusively on their own work and just be writers. That's a worthy goal. We should let them.

4. Perhaps most importantly, although the turn to teaching encourages faculty to reflect on the relationship between their writing practices and their teaching practices, they should not assume that their students are just like them. Faculty often experience the shock of recognition and a surge of compassion when they consider that, like them, their students may need and deserve a supportive community, shared language, repertories rather than rules, and reflective practice. However, at the same time, we balance this insight with the equally important principle that their students, like them, are autonomous knowers and may in some ways be unlike them too.

Finally, it's worth noting that many of the faculty insights about teaching we're about to share here will not seem particularly groundbreaking from a pedagogical perspective. Readers of this article will no doubt be familiar with the deep well of relevant scholarly knowledge about teaching and learning writing; many of you already lead educational development programs about these good ideas and effective practices. What matters is that the faculty we discuss became 
persuaded to take a fresh look at their students and their teaching. Having positive learning experiences as writers in a well-designed learning environment among other writers in a supportive community, they could relate to their own students as fellow learners and writers. The turn to teaching motivates faculty to consider how they can invite students to become writers and to participate in a community of writers: to discover what's entailed in making and sharing ideas in language, with all of the challenges and joys therein.

\section{Gloria*: Letting People Help}

Gloria is a performing artist, program director, and full professor with a deep record of creative, administrative, and professional accomplishments. She's known as a problem-solver who gets big things done and for effectively communicating and collaborating with students and faculty. Yet, as a writer, Gloria typically wrote alone. She felt isolated and dreaded writing-it was different from the way that she usually worked, but it was the only way she'd ever written.

When Gloria attended her first faculty writing retreat, she was motivated to try something new: writing in the same space with other people. But she was skeptical that changing where she wrote or just writing with others in the room would make a significant difference. From her perspective, she just needed to sit down and write. Maybe she was struggling because she just didn't like to write. She had not published in a peer review academic journal before she came to the retreat. Maybe she could only express herself through her creative work and her leadership. Still, she wanted to try because she felt that she had something to say.

At the retreat, she wrote among other writers, and she began to feel motivated, hearing the tap, tap, tap of fingers on keys on the keyboard and, sometimes, sighs of exasperation. This felt different, she recalled, more like a shared enterprise. Perhaps everyone was sharing a struggle, but the collective effort showed her that writing doesn't have to be a solitary struggle. 
Additionally, Gloria was skeptical that people in other disciplines could provide useful feedback, especially at an early stage in the work, when she was still unsure and figuring things out. But she agreed to participate in a writing exchange and feedback workshop offered during the retreat. She and two other writers talked about what they were working on and why. When it was her turn to share, she told them that she was utterly stuck, what she thought the problem was, and why these readers couldn't possibly help. It was a big conceptual problem that required expertise in her field, and she needed to rethink it from the ground up, alone. But the two readers were excited and curious about what they just read, and they asked questions that indicated that they understood it and found it interesting. Gloria began the workshop thinking that she had a draft with two ideas impossible to reconcile, and by the end, thanks to practical suggestions from her readers, she saw that she could fix the issues with better cueing and transitions. She was surprised at how helpful a conversation about her writing with faculty outside her field was. It was meaningful to her. She still talks about that moment at the faculty writing group she attends regularly: "You never know what other people know."

Our retreats promote these moments of insight. It is at the heart of what we do. This is learning that belongs to Gloria because it happened within her, on her own terms, in an authentic writing experience.

These are also the moments when faculty can be guided toward the turn to teaching. Occasionally during the workshop, we gently ask about participants' students. We might ask if they have students who struggle with issues that we discuss or if the way that they are teaching may in fact be rooted in their own beliefs or habits. Sometimes, faculty have "aha moments" right on the spot. For others, we find that it happens more slowly. For Gloria, during the retreat, she began to wonder if maybe it wasn't helpful to her student writers that she was their only audience, and only at the moment of project submission. Is she reproducing for her students the idea that there's only one way to write (alone)? In exercising complete control over feedback for her 
students, Gloria was in fact isolating her students and keeping them from finding other resources and readers.

As a result, Gloria began to explore how to make space for students to give one another feedback in the early stages of writing when they may still be unsure and figuring things out. She also shared with her students stories of her own writing experiences about the limitations of writing alone and trying to solve writing problems alone. She became curious about how students write.

This example demonstrates that experiential learning is one of the ways writers make connections between their writing and teaching. Gloria had to experience writing within a community of writers but also have the time and framework to reflect on that experience, which the retreat provides.

\section{Sam: Teaching Revision and Promoting High Standards}

Like Gloria, Sam also struggled with asking for feedback. An assistant professor in health sciences, Sam has attended almost all of the annual writing retreats. Once, when she was a graduate student in the sciences, she had written several chapters of her dissertation. After finishing each chapter, she asked her advisor for feedback. However, he did not provide any feedback on any of her writing for almost a year. When he finally did read it, he only told her that it was just not good enough and she needed to make major changes at the conceptual level. She found this feedback demoralizing and frustrating. She felt she wasted so much time.

Sam is a published scholar with an active research program, one she supports in large part with successful grant applications. She expects her work to meet the high standards of her field. Of course, she agrees that her dissertation chair should have honestly assessed the quality of her work. And, at the time, Sam was more than willing to rethink and revise. The problem was not that her chair was rigorous. The problem was that by responding so harshly, so late, and with so little attention to the drafts themselves, after so much time and effort 
had been expended on them, her advisor made it very difficult for her to revise effectively and efficiently. More importantly, this style of feedback did not help Sam learn how to revise the long, challenging scholarly projects to come over the course of her career.

Not surprisingly, Sam learned to resist the idea that she could and should share rough drafts for feedback. She instead formed a strongly held belief that work needed to be highly polished and near completion before sharing it. She described herself as fearful and as a perfectionist. Like Gloria, she developed a writing process in which she worked on her own as much as possible for as long as possible: "I just kep[t] editing and trying to revise when I [was] generating the stuff and it took] up so much time," she recalls. "Which is so easy to do and it feels like you're kind of doing something but it's not actually a good use of time or helpful to the project."

At one of our writing retreats, Sam participated in a workshop about how to give and get useful feedback on works in progress. She was initially reluctant. All the resistance kicked in: I don't want to share my work; this is scary and embarrassing; my colleagues are not going to know what I'm talking about; this is really bad writing. But she jumped in and began to realize that people can be generous and helpful. They, too, feel vulnerable when they share work that needs work. Feedback was also more efficient-she wasn't taking up so much time "generating stuff" and instead made "good use of her time."

Sam then began to build her repertoire of techniques for getting helpful feedback. In our retreats, we help faculty to name and to ask for what they need from readers. It helps the writer to assess where they are in their thinking and texts, to maintain control of their work, and to find the best readers for targeted feedback that they need. Now Sam regularly participates in writing groups and uses her skill in cultivating readers: she asks for what she needs from them when she shares her work, and she focuses their attention on where she's stuck and what she wants them to consider rather than an open-ended read that might prompt feedback that's not useful for her. (These skills also serve her well as a frequent co-author, often one of many in her grants 
and funded research, because they help collaborators to use the feedback process as a way to work together on a draft.)

Faculty members' experiences in graduate school shaped them as writers, for better and for worse. In our retreats, they discover strongly held beliefs and formative moments that drive their process. Sam learned that important readers would not read early work and that feedback could be as harsh as it was unhelpful. In response, she did not share early work, nor did she seek out feedback to advance her projects because it did not serve her well. She was not taught alternative strategies that might have helped. If graduate school is where she would learn to be a scholar, then that was just how scholarly writing worked.

But as Sam discovered that there were other ways to write, she began to wonder whether her feedback was helping her students to make progress. Unlike her dissertation chair, she devoted a lot of time providing feedback on drafts. She wanted to help students to finish their projects and develop effective skills, and she often relied on them as co-authors. If their work was advancing, so was hers. But it often wasn't. Why weren't they taking her feedback and revising the work as she instructed? Why were they just fixing superficial issues rather than truly revising?

Sam recently told us about an exchange with a graduate student co-author. They were taking turns exchanging an article draft. Although they agreed to revise substantive sections in order to clarify a case study's implications, the graduate student focused only on surface-level editing. When Sam returned it to him and pointed out that he hadn't actually revised the draft in the ways that they planned, he made some additional surface-level changes and sent it back again.

Sam was frustrated but also knew that the graduate student wouldn't learn necessary revision skills if she just did the work for him. So she drew on something else she learned in our retreats: that revision and editing are often different types of activity. Many writers are often more comfortable with editing than revising and revert to editing 
activities when they really need to revise. In addition, she learned that writers often stall when they try to revise and edit at the same time because the two activities entail different ways of engaging with the text. Maybe the student just didn't know how to revise and reverted to editing because that was something he could do.

So Sam took a different tack. She explained the difference between revising and editing, a distinction he had not known. "He thought, 'I'm done,'" Sam said. "But I had to do a lot of revision, and I think he was surprised because it involved massive restructuring and reorganization." They talked through the ways that rethinking was related to restructuring so that rethinking was connected to the writing itself. "So the writing retreat and everything has helped me see how to help him think about that because I'm better at doing it myself. I see the value of it, and I try to separate [the revising] from the editing."

In our retreats, we establish a shared language around the writing process, one that faculty can apply to the specific context of their own writing and research and one that faculty can use with their students in the feedback process. As Sam noted:

Probably in the past I would have done the whole thing together [editing and revising], but I try to keep that more distinct now. To help him see that. I even wrote a comment in the margin at one point when we went around 4 or 5 times, and I said, "Remember, revising can mean drastically changing. It's not good enough to think this is it. . . you can't just send it back with edits. Editing is not revising." . . . So that is massive because I then had this language that I could use that I implement myself and he could see me implementing it. I had this language to use to describe it to him.

Sam also redesigned her graduate seminars. She revised her assignments to include more time for getting feedback on a draft early in the process and time to work with that feedback. She now structures feedback opportunities as conversations, not just a fix-it list. In all her encounters with graduate student writers, she focuses on teaching 
them that feedback is powerful by showing them how they can use it to make progress. She has always had high expectations, and she is teaching graduate students how to meet them by teaching them how to revise rather than by fixing their work for them. She could do all the work herself; it would be more efficient and easier. By teaching graduate students how to get and work with feedback, Sam is teaching coauthorship as a writing process.

\section{Additional Turns to Teaching}

Many faculty believe that the writing process is linear: you begin with an idea, research it, write a draft, revise it, clean it up, and let it go. We use Hjortshoj's (2001) useful language for these phases of activity in the writing process: prewriting, composing, revising, editing, and release. Writers often arrive at retreats stuck in the prewriting phase; they feel unable to move into writing until they complete all of their research. As a result, they haven't written about their research for a long time and have built up a great deal of apprehension around composing. We've worked with many faculty who arrived at the workshop with baggage-figuratively and literally_arriving with suitcases, totes, boxes, and backpacks filled with articles, texts, and tattered notes. They have carried all of this-the unopened books and abandoned drafts, the guilt and self-recrimination-for years. It's heavy.

Writers arrive thinking that they need to fix themselves, to marshal the will, discipline, and intellect to just write and produce. But the problem is often that they are operating according to that linear model of the process. They are stuck in prewriting because they strongly believe that they must complete all their research before they write. In order to make progress on their writing, we teach them that they could in fact move through the phases in other ways. For people stuck in the prewriting phase, they can compose and even release-write down some ideas, draft some sections, share and talk about their work with trusted readers-even as they continue to research and think. All that 
matters is that they are making progress on their work, not stepping through each phase in a strict linear order.

In short, we help them to make visible and to confront their strongly held, tacit beliefs about the writing process. Not only does this help them to better manage their writing process and make progress, but it depersonalizes writing stalls and challenges. As one writer put it, "I was able to see that I had stalled myself during the prewriting phases and personalized the belief that I was unable to write." They learn that they can expand their repertoire of process-learn and experiment with new ways of thinking and writing. There's no one right way to write, and there is nothing wrong with the writer. Instead, there are issues that arise and strategies to try in order to address them. It's a tremendous relief to put that baggage down.

When faculty realize that their strongly held beliefs about how writing must happen interfere with making writing happen at all, we can invite them to consider if they are teaching their students a rigid linear model of the writing process. After all, the linear model is often embedded in assignments across the disciplines that treat a writing project as a series of locksteps. Do they expect their students to complete all their research before they begin to write? Do they leave time and give feedback on early rough drafts so that students can return to prewriting for further research? Are they curious about how their students approach the writing process, where and why students might get stalled, and how they might help students to make progress?

In the turn to teaching, faculty can become more interested in their students' experiences of writing. In our retreats, we take an interest in faculty writing experiences. They discover firsthand the power of observing their own processes, seeing their actions as choices, and analyzing the results. Faculty feel relieved that they can depersonalize writing challenges and confront the very real stresses of academic writing. "I was just reminded once again," one frequent retreat attendee shared, "that writing is very hard work that takes time, not just for me but for everyone. It is lovely to get that affirmation. I love writing. The 
stress I feel with it comes from my perception that I have to do it more quickly in order to satisfy the requirements of my job, so I like being in spaces where people acknowledge that writing takes time."

Writing takes time for students too. Nevertheless, many faculty design classes that could be described as relentless-one assignment after another, without time to go back or to rest and reflect. Many writers in the retreat discover that they cannot keep up a relentless pace of production and that their work benefits when they slow down. Some find it useful to set aside drafts for a bit and then return to them with fresh eyes. Others find that more rest makes them more productive and happy. Many find that doing less work lets them do better work. But when they turn to their teaching and consider how their students are experiencing their own writing assignments, they often find that they have designed courses at a breakneck pace, stuffed with content, and loaded with deadlines at the busiest times in the semester. They are creating the very environment for learning under which they have suffered.

Most of our retreat participants feel pressured. If we could magically grant them one wish, they would ask for time. There is tremendous pressure to publish as much as possible. Quantity and volume matter. At the same time, they are busy, and their lives are complex, and they seek balance between and among their roles. But for most participants, time doesn't give them what they're seeking: a sense of meaning in their work.

At the end of one retreat, Marie shared her realization that her students may also feel this way as writers-going from class to class, final paper to final paper, senior thesis to graduation. Maybe they weren't feeling connected to their work, beyond the brute goal of completing the product? Marie didn't want to contribute to the cult of productivity and the culture of superficial performance. She wanted them to consider why they were researching and writing their particular projects, to have a sense of meaning and purpose. She now includes class conversations about what motivates good writing topics, how to connect their interests with the assignment parameters, and to consider what they're curious about. 
It's not just the what and the how much but also the why that keep us going. And the why can be learned, if it is taught.

\section{Conclusion: Toward an Integrative Approach}

When we help faculty to improve one aspect of their professional lives, such as their writing, they can connect that learning to other aspects of their work, such as their teaching. Through this promising integrative approach, educational developers can support faculty across roles and responsibilities. In this case, when we improve how faculty experience writing, we can also help them to change how they teach writing. By having empowering learning experiences in our retreats that make a real difference in their writing lives, faculty discover that their students also deserve nothing less.

*Names of participants and identifying information have been changed.

\section{Biographies}

Jennifer Ahern-Dodson is an Assistant Professor of the Practice in Writing Studies in the Thompson Writing Program at Duke University and is the founding director of the Duke Faculty Write Program. She earned her $\mathrm{PhD}$ in English, with a specialization in Rhetoric and Composition, from Florida State University. In her research, she studies how community shapes writers' lives and practices. Through this work, she is committed to cultivating communities that not only are supportive to writers but also promote rigor, creativity, critical reflection, and community engagement.

Monique Dufour is a Collegiate Assistant Professor in the Department of History at Virginia Tech, where she teaches the history of medicine and writing. She also facilitates workshops and consults with faculty and graduate students as writers and teachers. Before completing her $\mathrm{PhD}$ in Science and Technology Studies, she was a faculty development 
consultant at Virginia Tech's Center for Excellence in Undergraduate Teaching. Her book, Sustainable Teaching: Time Management for Passionate Educators, is under advance contract with the Teaching and Learning in Higher Education series at West Virginia University Press.

\section{Acknowledgments}

We are grateful to all the writers who participated in our faculty writing retreats for their generosity, honesty, and presence.

We thank all the staff whose administrative and professional support at Duke University and Virginia Tech made this work possible. Thanks also to the Office for Faculty Advancement and the Office of the Dean of Trinity College at Duke University for their support and funding of the Faculty Write Program retreats.

\section{References}

Belcher, W. L. (2009). Reflections on ten years of teaching writing for publication to graduate students and junior faculty. Journal of Scholarly Publishing, 40, 184-199.

Boice, R. (1990). Professors as writers: A self-help guide to productive writing. New Forums.

Dufour, M., \& Ahern-Dodson, J. (2017). Good writers always follow my rules. In C. E. Ball \& D. M. Loewe (Eds.), Bad ideas about writing (pp. 121-125). West Virginia University Libraries.

Elbow, P., \& Sorcinelli, M. D. (2006). The faculty writing place: A room of our own. Change, 38, 17-22.

Geller, A. E., \& Eodice, M. (Eds.). (2013). Working with faculty writers. Utah State University Press.

Girardeau, L., Rud, A. G., \& Trevisan, M. S. (2014). Jumpstarting junior faculty motivation and performance with focused writing retreats. Journal of Faculty Development, 28, 33-40.

Gray, T. (2005). Publish and flourish: Become a prolific scholar. New Mexico State University Press.

Hjortshoj, K. (2001). Understanding writing blocks. Oxford University Press. 
Jensen, J. (2017). Write no matter what: Advice for academics. University of Chicago Press.

Maheux-Pelletier, G., Marsh, H., \& Frake-Mistak, M. (2019). The benefits of writing retreats revisited. In N. Simmons \& A. Singh (Eds.), Critical collaboration communities: Academic writing partnerships, groups, and retreats. Brill Sense.

McGrail, M. R., Rickard, C. M., \& Jones, R. (2006). Publish or perish: A systematic review of interventions to increase academic publication rates. Higher Education Research and Development, 25(1), 19-35.

Moore, S. (2003). Writers' retreats for academics: Exploring and increasing the motivation to write. Journal of Further and Higher Education, 27, 333-342.

Moore, S., Murphy, M., \& Murray, R. (2010). Increasing academic output and supporting equality of career opportunity in universities: Can writers' retreats play a role? Journal of Faculty Development, 24, 21-30.

Murray, R., \& Newton, M. (2009). Writing retreat as structured intervention: Margin or mainstream? Higher Education Research and Development, 28, 541-553.

Silva, P. (2007). How to write a lot: A practical guide to productive academic writing. American Psychological Association.

Simmons, N., \& Singh, A. (Eds.). (2019). Critical collaborative communities: Academic writing partnerships, groups, and retreats. Brill Sense.

Sorcinelli, M. D., Gray, T., \& Birch, A. J. (2011). Faculty development beyond instructional development: Ideas centers can use. To Improve the Academy, 30, 247-261.

Sword, H. (2017). Air and light and time and space: How successful academics write. Harvard University Press.

Tulley, C. E. (2018). How writing faculty write: Strategies for process, product, and productivity. Utah State University Press.

Werder, C. (2013). The promise of self-authorship as an integrative framework for supporting faculty writers. In A. E. Geller \& M. Eodice (Eds.), Working with faculty writers (pp. 279-292). Utah State University Press. 
